\title{
O aluno do PROEJA no município de Muriaé: Escola Municipal "Professora Odaléia Morais de Azevedo"
}

\author{
Raquel Veggi Moreira ${ }^{1}$ e Larissa Mendonça Lirioº
}

1 Mestre em Cognição e Linguagem (UENF). Pós-graduanda em Planejamento, Implementação e Gestão de EaD (UFF). Advogada, especialista em Direito Civil. Brasil. E-mail: rveggi@yahoo.com.br

2 Mestre em Cognição e Linguagem (UENF). Pós-Graduação em Alfabetização e Letramento nas séries iniciais e na EJA (Instituto Superior de Educação de Afonso Cláudio). Licenciatura Plena em Pedagogia (UFES). Brasil. E-mail: larissalir@hotmail.com

RESUMO: O presente artigo tem como objetivo principal traçar um perfil do aluno do Programa Nacional de Integração da Educação Profissional com a Educação Básica na modalidade de Educação de Jovens e Adultos (PROEJA) da Escola Municipal "Professora Odaléia Morais de Azevedo", no município de Muriaé-MG. Optou-se como procedimento metodológico a revisão de literatura de cunho exploratório, bem como, a coleta de dados, através da aplicação de questionário, e a análise dos dados foi quantificada utilizando-se estatística simples, em amostra de 55 estudantes da Educação de Jovens e Adultos (EJA). Observou-se que a maioria dos alunos é do sexo feminino, entre 41 e 62 anos e compreendem esse espaço como uma oportunidade de melhoria de vida. A qualidade do ensino para esse público precisa passar pela boa gestão e qualificação dos docentes, além da motivação e atratividade para os discentes, com a finalidade de alcançar, cada vez mais, melhores resultados no processo ensino-aprendizagem, além disso, é preciso que os professores considerem a diversidade desses alunos.

Palavras-chave: EJA. Permanência. Diversidade.

\section{Profile of the PROEJA student at the Municipal School "Professor Odaléia Morais de Azevedo" in the city of Muriaé-MG}

ABSTRACT: The current article has as main aims identify the student profile of the National Integration Program of Professional Education with Basic Education in the Adult and Youth Education mode (PROEJA) of the Municipal School "Professor Odaléia Azevedo de Morais" in the Muriaé-MG city. Was chosen as methodological procedure the literature review with exploratory focus, as well as data collection through of questionnaire application and the data analysis was quantified using simple statistics in a sample of 55 students from Adults and youths Education (EJA). It was observed that most of the students are female, between 41 and 62 years old and understand it as an life opportunity life. The quality of education for this audience needs to have good management and teachers qualified, as well as motivation and attractiveness to students, in order to achieve increasingly better results in the teaching-learning process, moreover, it is necessary that teachers consider the students diversity.

Keywords: Youth and Adult Education. Permanence. Diversity.

\section{INTRODUÇÃO}

Há muito se fala sobre alfabetização de jovens e adultos no Brasil, tendo sido implementados vários programas pelo Ministério da Educação (MEC) ao longo de déca- 
das, sempre com novas metodologias pedagógicas, como a Campanha de Educação de Adolescentes e Adultos (CEAA), entre 1952-1963, uma campanha cujo alvo era a população estabelecida na zona rural, considerada na época (1952), um programa de vanguarda voltado à alfabetização de adolescentes e adultos, que atendesse principalmente a área rural, onde o analfabetismo atingia níveis consideráveis.

Nesse mesmo período (1958-1963), foi criada a Campanha Nacional de Erradicação do Analfabetismo (CNEA) com programas que deveriam atingir várias faixas etárias, ao mesmo tempo. Entretanto, um dos programas de alfabetização mais conhecidos e divulgados no Brasil foi o Movimento Brasileiro de Alfabetização (MOBRAL), no período de 1967-1985, com a finalidade de erradicar o analfabetismo, em todo o território nacional. Outros programas continuaram a ser criados, como a Cruzada Ação Básica Cristã (Cruzada $A B C)$, Programa Alfabetização Solidária (PAS - 1996), ainda em vigor, o Programa Brasil Alfabetizado (2003), que ainda permanece em atividade e o Programa Nacional de Integração da Educação Profissional com a Educação Básica na Modalidade de Educação de Jovens e Adultos (PROEJA).

Este último é um programa com fins exclusivamente educacionais, com diversas ações públicas propostas nesse sentido, ao mesmo tempo com desafios políticos e pedagógicos. Inserido no contexto do PROEJA está a modalidade EJA, educação oferecida aos jovens e adultos que, por diferentes motivos, não concluíram o ensino fundamental e médio no seu devido tempo. O objetivo da EJA é oportunizar o acesso desse público ao ensino médio integrado à educação técnica-profissional de nível mé- dio.

O PROEJA foi instituído, inicialmente, pelo Decreto no 5.478/2005 e, em seguida, substituído pelo o de $\mathrm{n}$ - 5.840/2006, tem como objetivo principal ofertar cursos de Educação de Jovens e Adultos com Educação Profissional, para essas pessoas que não tiveram a oportunidade de cursar o ensino fundamental e/ou o ensino médio na idade regular e que busquem também uma profissionalização.

Todas essas campanhas ou programas, como são chamados, são de iniciativa do Governo Federal, através do MEC, que visam erradicar ou diminuir o número de pessoas analfabetas, através de políticas públicas, que sempre buscaram alcançar, principalmente, os excluídos que viviam em áreas rurais e bairros periféricos das grandes cidades, geralmente mediante cursos ministrados à noite ou em horários disponibilizados por escolas públicas de ensino fundamental, muitas vezes, incompatíveis com a disponibilidade de trabalhadores, que era o maior público desses programas.

A problematização da temática em questão partiu da premissa de que a educação de jovens e adultos se baseia em políticas públicas educacionais, ao longo do período de 1953 a 2006, buscando-se responder às seguintes indagações: qual o perfil dos alunos da EJA, no município de Muriaé-MG? Considera-se o PROEJA um bom programa de aprendizagem? Outra indagação referese aos motivos que levam ao analfabetismo e à baixa escolaridade de jovens e adultos que frequentam esses programas.

Portanto, o objetivo deste artigo é analisar o perfil do aluno do PROEJA da "Escola Municipal Professora Odaléia Morais de Azevedo", no município de Muriaé - MG, assim como as dificuldades encontradas no 
processo ensino-aprendizagem.

\section{METODOLOGIA}

Para atingir os objetivos propostos, optou-se por uma revisão de literatura sobre o processo da educação de jovens e adultos, mediante utilização de livros, artigos, periódicos, entre outras publicações, que tratam do tema, como também a Lei de Diretrizes e Bases da Educação Nacional (Lei no 9.394/96), nos artigos 37 e 38. Para tanto, foram feitos fichamentos, resumos, resenhas e análise de todo o material bibliográfico selecionado (ANDRADE, 2004; CARMO et al., 2008; FRIGOTTO, 2015; HADDAD; DI PIERRO, 2000; PAIVA, SOARES, BARCELOS, 2014). E valeu-se de questionário, também como instrumento de pesquisa, constituído de 10 questões objetivas, aplicado a quatro turmas da EJA, duas turmas do 6을 ano e duas do 8으, da Escola Municipal "Professora Odaléia Morais de Azevedo", no município de Muriaé - MG. A amostra foi constituída por 55 alunos, sendo 46 do sexo feminino e 09 do masculino. Utilizou-se estatística simples para análise dos dados, visto que fornece métodos para coleta, organização, descrição, análise e interpretação deles.

\section{A EDUCAÇÃO DE JOVENS E ADULTOS EM MURIAÉ-MG}

Os componentes curriculares da matriz curricular do PROEJA - Base Nacional Comum são: Língua Portuguesa, Matemática, História, Geografia, Ciências, Educação Religiosa, Educação Física, Língua Estrangeira Moderna (Inglês). Na parte diversificada, os conteúdos são: Informática, Técnicas Secretariais, Relações Públicas e Humanas,
Organização de empresas e Gestão de Negócios, sendo que essa se refere ao Curso de Secretariado oferecido pelo Instituto Federal de Educação, Ciência e Tecnologia do Sudeste de Minas Gerais (IFET), Campus Rio Pompa-MG. Trata-se de uma parceria realizada entre o poder público local e o IFET, através do Acordo de Cooperação Técnica no 07/2009, oportunizando aos alunos um curso profissionalizante. Para cada área, existe um docente; a carga horária é de 120 a 240 horas/aula, não podendo ultrapassar o período de 12 meses para sua completa execução, podendo ser realizado na modalidade de educação à distância.

Quanto à modalidade à distância, pode apresentar dificuldades à clientela da EJA, pois segundo Haddad (2000, apud CARMO et al., 2008, p. 34),

para um percentual significativo de alunos a representação que estes fazem da escola vai-se transformando com o passar do tempo: primeiro passam por um momento de expectativa antes do ingresso à escola; depois por um momento de decepção, de desânimo, culminando com a desistência, o que caracteriza os altos índices de evasão na EJA.

Em conversa informal com alguns alunos na escola, percebeu-se que muitos demonstravam cansaço ou desânimo, outros falavam que apesar de gostarem muito de voltar à escola, era muito "difícil e cansativo porque a gente trabalha muito durante o dia", disse uma senhora (64 anos), aluna da EJA, da Escola Municipal "Professora Odaléia Morais de Azevedo", Muriaé-MG.

Segundo o coordenador geral do PROEJA/Muriaé, essas queixas são recorrentes e, com a finalidade de evitar a evasão, fre-

https://periodicos.unifap.br/index.php/estacao Macapá, v. 6, n. 2, p. 117-126, maio/ago. 2016 
quentemente, são criadas atividades motivadoras, como por exemplo, utilização de filme contextualizado ao conteúdo da aula, palestra sobre temas diversos, como cidadania, mercado de trabalho e importância dos estudos. Nesse sentido, Dorneles (2005) apud Soares (2007, p. 8) diz que a educação não se exaure só na aprendizagem cognitiva e instrumental, mas abrange as aprendizagens sociais tão indispensáveis quanto às primeiras. Assim, é essa visão holística de educação, que abarca todas as extensões do ser humano, defendida por educadores e pesquisadores da educação nacional como sendo imprescindível para o século XXI. A autora explica que existe a necessidade de se lembrar constantemente os quatro pilares da educação: "aprender a conhecer, aprender a fazer, aprender a ser e aprender a viver em conjunto" (SANTOS, 2007, p. 8). Ainda que seja considerada uma utopia educacional, mesmo assim são indispensáveis para pensar o futuro dos cidadãos do mundo. Esses pilares remetem a uma realidade "a necessidade de estarmos em permanente processo educativo de sermos aprendizes ao longo da vida" (SANTOS, 2007, p. 8).

Para Valente (2004), a educação baseada na simples transmissão de informação não contribui para o desenvolvimento das competências e das habilidades necessárias, como também não tem condições de repassar o volume de informação gerado cotidianamente. Segundo o autor,

À medida que a sociedade vai tornandose cada vez mais dependente do conhecimento, é necessário questionar a concepção de educação e de aprendizagem. É importante entender a aprendizagem como uma atividade contínua, que esten- de ao longo da vida. A educação tem de criar condições para o aluno desenvolver a habilidade de aprender a aprender, de modo que ele seja capaz de continuar sua aprendizagem mesmo depois de deixar a escola (VALENTE, 2004, p. 13).

Mesmo sabendo que o acesso à educação, de maneira geral e em todos os níveis, vem ganhando espaço no Brasil, principalmente, depois da Constituição Federal de 1988, conhecida como "Constituição Cidadã", ainda assim, a educação está longe de ser ideal, sobretudo, no ensino básico, segmento em que acontece o maior índice de evasão escolar motivado pela necessidade de trabalhar, a falta de estímulo e atrativos na escola, e ainda no ensino médio, fase em que adolescentes e jovens, simplesmente, abandonam a escola, por fatores associados, como desempenho escolar insuficiente, comportamento inadequado no âmbito da escola, problemas familiares, ou a necessidade de trabalhar e complementar a renda da família.

De acordo com o Relatório de Desenvolvimento de 2012, o Brasil tem a terceira maior taxa de abandono escolar entre os 100 países com maior Índice de Desenvolvimento Humano (IDH). Inicialmente, vale ressaltar que a sociedade de maneira geral precisa compreender que a EJA é uma relação ensino-aprendizagem como outra qualquer, com diferenças no seu público alvo, que são jovens acima de 18 anos e adultos semianalfabetos e/ou analfabetos na acepção da palavra. Conforme observam Carmo e Pessanha,

após a transição de paradigmas, da LDBEN 5692/1971 para a LDBEN 9394/1996, as ações governamentais de atendimento 
as demandas da educação de jovens e adultos sofreram contração. Com políticas educacionais fragmentadas, descontínuas e irregulares, no período dos anos 1990, o governo brasileiro não assumiu o seu compromisso com este grupo e promoveu a desvalorização da EJA (CARMO; PESSANHA, 2014, p. 3).

Pelo o que parece, essa ressalva inicial fundamenta-se num "preconceito" em relação à EJA, que, ao contrário, deveria servir de incentivo e, até mesmo de orgulho, para aqueles que nunca conseguiram ter acesso a um livro, à educação, o que deveria ser natural, conforme determina a Constituição Federal de 1988 sobre os direitos fundamentais individuais e coletivos explícitos e implícitos, como nos artigos que se seguem:

Art. 6o: São direitos sociais a educação, [...] na forma desta Constituição;

Art. 205: A educação, direito de todos e dever do Estado e da família.

Art. 206: O ensino será ministrado com base nos seguintes princípios: [...] IV gratuidade do ensino público nos estabelecimentos oficiais.

Art. 208 que traz: O dever do Estado com a educação será efetivado mediante a garantia de:

I - ensino fundamental, obrigatório e gratuito, assegurada, inclusive, sua oferta gratuita para todos os que a ele não tiveram acesso na idade própria;

$\mathrm{VI}$ - oferta de ensino noturno regular, adequado às condições do educando (BRASIL, 1988, p. 10, 80-81).

Segundo Cretella Jr., o art. 208, §1ㅇ da vigente Constituição Federal não deixa dúvida a respeito do acesso obrigatório e gratuito que o educando tem, em qualquer nível de ensino, cumprindo os requisitos legais, tem direito público subjetivo ao ensino, oponível ao Estado, não podendo ele negar a solicitação, protegida por expressa norma jurídica constitucional (CRETELLA, 1993 , p. 4418). Reiteradas vezes, o legislador constituinte fez questão de dizer que a "educação é direito de todos", incluindo essencialmente, a responsabilidade do Estado como gestor desse direito social num Estado de Direito, democrático, inclusive, conforme lição de Alexandre de Moraes, a Constituição Federal proclama que:

educação é direito de todos e dever do Estado e da família, devendo ser promovida e incentivada com a colaboração da sociedade, visando ao pleno desenvolvimento da pessoa, seu preparo para o exercício da cidadania e sua qualificação para o trabalho (MORAES, 2005, p. 2083).

Para regulamentar este direito, já determinado pela Constituição Federal, promulgou-se em 20 de dezembro de 1996, a Lei de Diretrizes e Bases da Educação Nacional (LDBEN) - Lei no 9.394/96, artigos 37 e 38 (in verbis):

Art. 37. A educação de jovens e adultos será destinada àqueles que não tiveram acesso ou continuidade de estudos no ensino fundamental e médio na idade própria.

$\S 1$ O Os sistemas de ensino assegurarão gratuitamente aos jovens e aos adultos, que não puderam efetuar os estudos na idade regular, oportunidades educacionais apropriadas, consideradas as características do alunado, seus interesses, condições de vida e de trabalho, mediante cursos e exames.

§ 20 O Poder Público viabilizará e estimulará o acesso e a permanência do traba-

https://periodicos.unifap.br/index.php/estacao Macapá, v. 6, n. 2, p. 117-126, maio/ago. 2016 
Ihador na escola, mediante ações integradas e complementares entre si.

$\S 3^{\circ}$ A educação de jovens e adultos deverá articular-se, preferencialmente, com a educação profissional, na forma do regulamento.

Art. 38. Os sistemas de ensino manterão cursos e exames supletivos, que compreenderão a base nacional comum do currículo, habilitando ao prosseguimento de estudos em caráter regular.

$\S 1$ 을 Os exames a que se refere este artigo realizar-se-ão:

I - no nível de conclusão do ensino fundamental, para os maiores de quinze anos;

II - no nível de conclusão do ensino médio, para os maiores de dezoito anos.

$\S 2$ o Os conhecimentos e habilidades adquiridos pelos educandos por meios informais serão aferidos e reconhecidos mediante exames (BRASIL, 1996, p. 20).

Haddad e Di Pierro explicam que:

[...] a reforma educacional iniciada em 1995 veio sendo implementada sob o imperativo de restrição do gasto público, de modo a cooperar com o modelo de ajuste estrutural e a política de estabilização econômica adotados pelo governo federal. Tem por objetivos descentralizar os encargos financeiros com a educação, racionalizando e redistribuindo o gasto público em favor do ensino fundamental obrigatório. Essas diretrizes de reforma educacional implicaram que o MEC mantivesse a educação básica de jovens e adultos na posição marginal que ela já ocupava nas políticas públicas de âmbito nacional, reforçando as tendências à descentralização do financiamento e da produção dos serviços (HADDAD; DI PIERRO, 2000, p. 122).
Entretanto, o acesso à educação implica vários fatores como, por exemplo, o aluno jovem ou adulto ter condições de frequentar uma escola - questão que aflige milhares de brasileiros em idade adulta e vivenciada tanto no cotidiano familiar, quanto na vida em comunidade.

\subsection{Perfil do aluno da EJA/Muriaé-MG}

De acordo com o Projeto Pedagógico, a EJA, no município de Muriaé-MG, funciona nas instalações da Escola Municipal "Professora Odaléia Morais de Azevedo", onde há 4 salas disponibilizadas, cada uma com capacidade para 30 alunos, espaço considerado adequado pela Secretaria Municipal de Educação. Possui biblioteca com acervo considerável para atender as necessidades dos alunos da EJA e dos demais do ensino fundamental e médio.

A matrícula na EJA é vista como uma oportunidade de melhoria de vida. Muitos jovens e adultos se sentem inseguros, se retraem nesse novo contexto de vida, principalmente em relação ao emprego, à importância do estudo para a sua vida e inserção no mercado de trabalho. A média de idade nas quatro turmas (6음 ano $A$ e $B$ e $8^{\circ}$ 은 ano $A$ e $B$ ) é de 41,62 , entre homens e muIheres.

Os resultados demonstrados no Gráfico 1 apontam que $83,64 \%$ dos alunos são do sexo feminino, em relação a $16,36 \%$ do sexo masculino, o que, supostamente, mostra que as mulheres têm mais interesse pelos estudos ou que os homens, ou dão mais importância ao trabalho do que aos estudos. 
Gráfico 1: Gênero dos alunos entrevistados EJA/Muriaé-MG. Graph 1: Gender of the students interviewed EJA/Muriaé-MG.

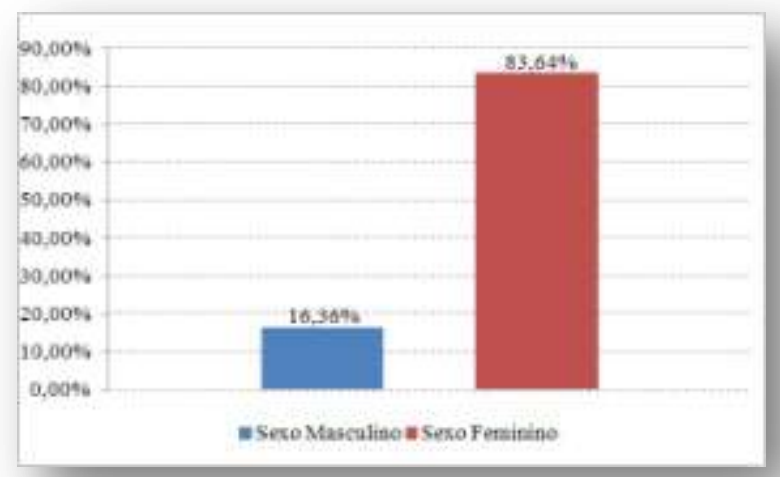

Fonte: Dados da pesquisa, março/2015.

Pelos resultados do Gráfico 2, verifica-se que a maioria $(47,27 \%)$ dos alunos são casados ou vivem em união estável; $34,24 \%$ são solteiros e $18,19 \%$ são divorciados ou separados. Os casados, de ambos os sexos, disseram que é muito difícil conciliar trabalho e estudo. As mulheres acrescentaram que, além disso, têm os serviços domésticos, que demandam muito tempo durante o dia e acabam comprometendo o desempenho e a frequência escolar.

Gráfico 2: Estado civil.

Graph 2: Marital status.

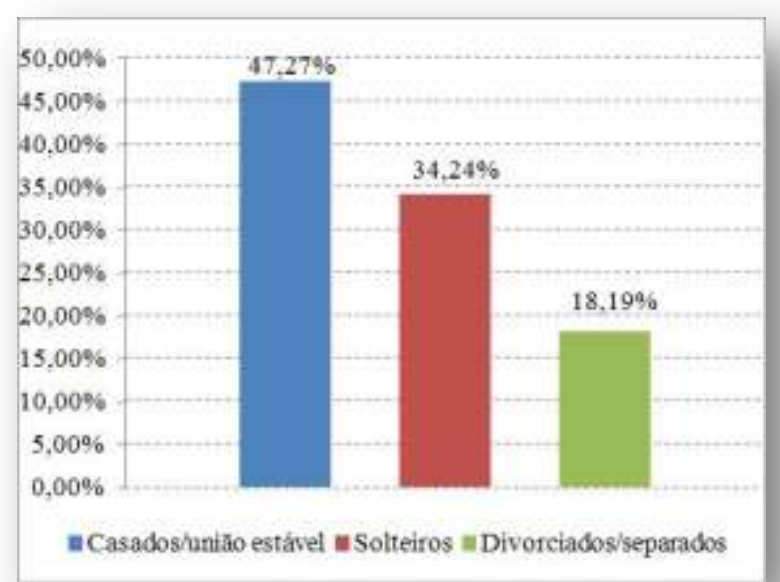

Fonte: Dados da pesquisa, março/2015.

Percebe-se no Gráfico 3, que a maioria, em ambos os sexos, ficou fora do ambiente escolar por mais de 3 anos. Houve relatos, principalmente, entre os homens que ficaram "sem estudar mais de 30 anos". Hoje, enfrentam muita dificuldade em "aprender o que os professores ensinam".

Gráfico 3: Tempo fora do ambiente escolar.

Graph 3: Time away from the school environment.

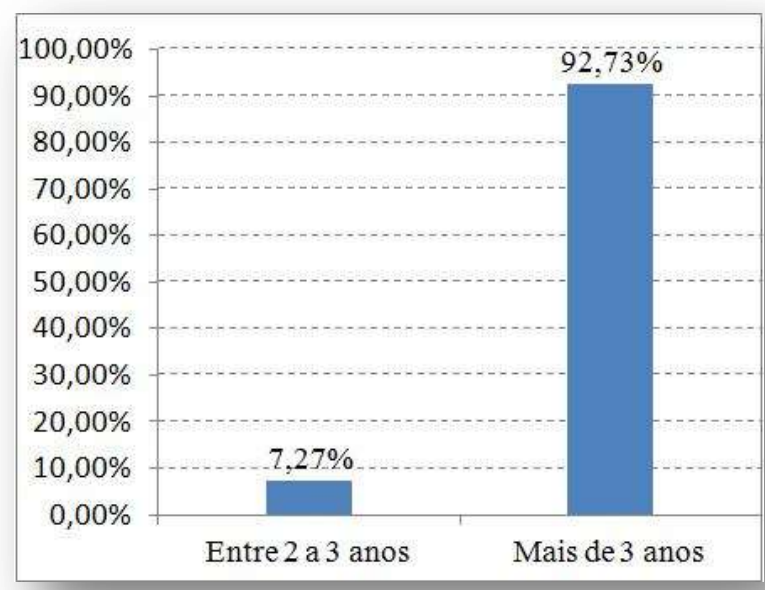

Fonte: Dados da pesquisa, março/2015.

No Gráfico 4, os resultados mostram que 94,55\% dos alunos da EJA não têm incentivo e/ou motivação por parte de parentes e amigos para estudar. Apenas 5,45\% disseram que as famílias incentivam a continuarem os estudos, após conclusão deste programa (PROEJA). Segundo Paiva (2014, p. 19), "pensar sujeitos que aprendem continuadamente - pela via da educação continuada - remete a um campo mais amplo, que se organiza a partir dos sujeitos a quem atende, o da educação de jovens e adultos." 
Gráfico 4: Incentivo/motivação para estudar.

Graph 4: Incentive/motivation to study.

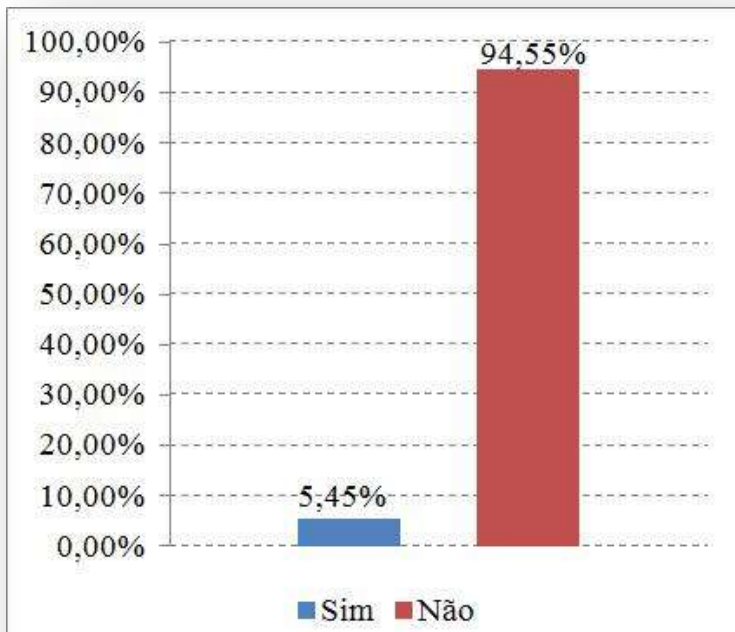

Fonte: Dados da pesquisa, março/2015.

No Gráfico 5, os resultados mostram que a maioria $(83,65 \%)$ disse que voltariam a estudar para ter melhor qualificação e, com isso, "melhorar de emprego e ter melhor salário. "Concluir o ensino médio 7,27\%; fazer pós-graduação 3,63\% e fazer faculdade $5,45 \%$.

Gráfico 5: Aspirações com os estudos. Graph 5: Aspirations with the studies.

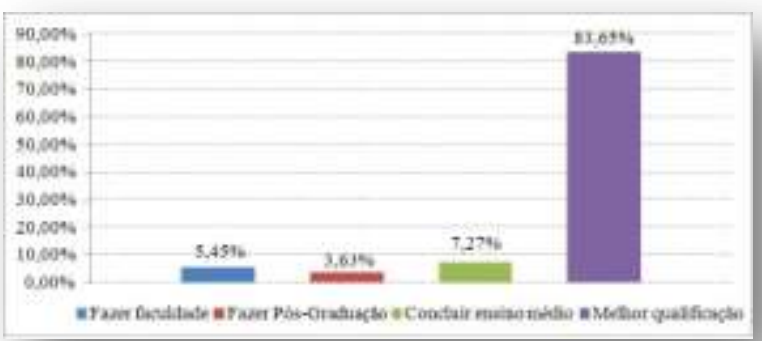

Fonte: Dados da pesquisa, março/2015.

A sua maneira, todos buscam um ideal comum - melhorar de vida, ter um bom emprego e, consequentemente, um bom salário.

Os resultados mostram que $74 \%$ dos en- trevistados consideram a aprendizagem ótima; $20 \%$ boa; e, apenas 6\%, regular (Gráfico 6). Esse pequeno percentual de estudantes representa mais dificuldade em aprender os conteúdos, mas, mesmo assim, apresentam interesse e assiduidade.

Gráfico 6: Aprendizagem.

Graph 6: Learning.

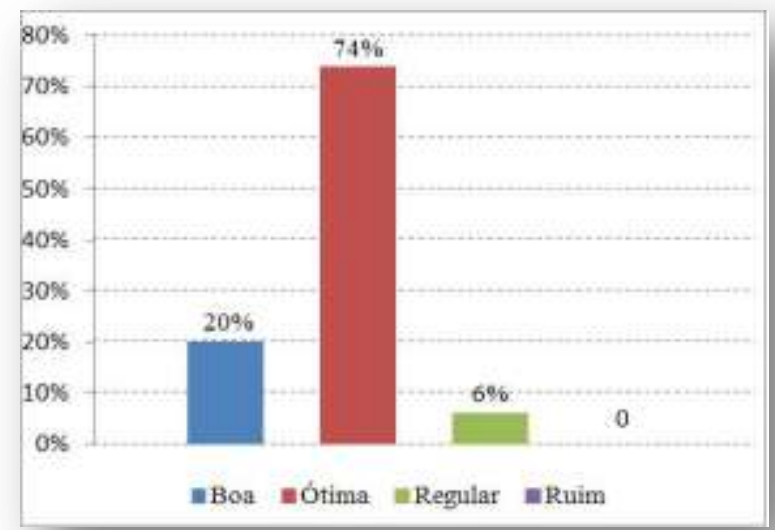

Fonte: Dados da pesquisa, março/2015

Vale ressaltar que a aprendizagem desses jovens e adultos não pode se restringir apenas a um processo de aquisição de conhecimento, de conteúdos e informações. É preciso ir além. É uma percepção que engloba todas as áreas dos indivíduos, em particular para esse público, uma vez que a maioria tem um histórico de vida complexo, envolvendo perdas, situações de conflitos familiares e sociais (DORNELES, 2005).

Sobre o motivo de estudarem, à noite, foi unânime o fato de trabalharem durante o dia. Algumas mulheres trabalham em confecções na cidade com carga horária de até dez horas diárias. O mesmo acontece com dois alunos do sexo masculino que são motoristas e trabalham, em média, nove ou dez horas/dia. Eles disseram que é muito difícil cumprir o horário de trabalho e não "chegar atrasado à aula, mas que não 
vão desistir". "O trabalho assalariado representa vetor de dignidade humana e, nas sociedades contemporâneas, é fundamento de cidadania econômica, estando também no princípio da cidadania social", como bem assinala (ANDRADE, 2004, p. 141). Nesse sentido, Frigotto (2015, p. 214) afirma que "o econômico não é concebido como um fator, mas como a relação social fundamental, mediante a qual o ser humano pelo trabalho produz as condições materiais de sua produção e reprodução como ser da natureza".

Unanimidade também sobre a qualidade do PROEJA, todos consideram o programa uma ótima oportunidade de estudar "para melhorar de vida".

É preciso que a sociedade entenda a importância dessa modalidade, que vislumbre a possibilidade de se mudar significativamente a vida das pessoas através do ensino-aprendizagem.

\section{CONCLUSÃO}

Considerando-se o objetivo estabelecido para este artigo, qual seja, verificar o perfil dos alunos jovens e adultos da EJA/MuriaéMG, entende-se que foi atendido pela pesquisa realizada.

Os resultados mostraram que alunos têm dificuldades em conciliar trabalho e escola, mas demonstram a vontade de cursar graduação, pós-graduação, mas principalmente, melhorar a qualificação. Se por um lado, todos os alunos pesquisados almejam melhoraria de vida, conquista de bom emprego e obtenção de bom salário, o que representa um grande desafio para a vida contemporânea, por outro lado, aumenta a responsabilidade para a escola e professores, pois a clientela é, inegavel- mente, diferenciada.

O PROEJA na escola pesquisada ainda se mostra caminhando para alcançar ou se aproximar do necessário e ideal. Um dos problemas identificados nesse programa é certa dificuldade de alguns professores para lidar com esse público específico, diante da diversidade e diferenças culturais, socioeconômicas existentes entre os alunos.

Diante disso, percebeu-se que a qualidade do ensino para esse público precisa passar pela boa gestão, qualificação dos docentes, motivação e atratividade para os discentes, com a finalidade de alcançar cada vez mais, melhores resultados no processo ensino-aprendizagem. Além disso, é preciso que os professores considerem a diversidade desses alunos. São necessários diálogos constantes entre escola-professores-alunos. Portanto, é de suma importância conhecer e entender suas dificuldades individuais e coletivas.

A expectativa de vida que eles têm em relação à aquisição de conhecimentos é enorme. Eles não querem só aprender, mas buscam, antes de tudo, participar da sociedade, serem sujeitos de direito. Nada demais! É o que todos os brasileiros deveriam ser e ter: dignidade, em um Estado Democrático de Direito, cumprindo o ideal insculpido no art. 205 do texto constitucional que prevê: "A educação, direito de todos e dever do Estado [...]" (BRASIL, 1988, p. 80). Educação, em essência, transforma o sujeito e integra-o à sociedade.

\section{REFERÊNCIAS}

ANDRADE, E. R. A Educação de Jovens e Adultos e os Jovens do "Último Turno": produzindo outsiders. 2004. 220f. Tese [Doutorado em Educação] - Faculdade de

https://periodicos.unifap.br/index.php/estacao Macapá, v. 6, n. 2, p. 117-126, maio/ago. 2016 
Educação da Universidade Federal Fluminense, Niterói, 2004.

BRASIL. Constituição. Constituição da República Federativa do Brasil. Brasília, Senado Federal: Centro Gráfico, 1988.

. Ministério de Educação e Cultura. LDBEM - Lei no 9.394/96, de 20 de dezembro de 1996. Estabelece as diretrizes e bases da Educação Nacional. Brasília: MEC, 1996.

. MEC/SETEC. Programa Nacional de Integração da Educação Profissional com a Educação Básica na Modalidade de Educação de Jovens e Adultos: Formação Inicial e Continuada/Ensino Fundamental. Documento Base. Brasília, agosto, 2007.

CARMO, G. T. do et al. Educação de Jovens e Adultos: marcas de cidadania no povoado de Rio Preto. Revista Perspectiva online, v. 5, n. 1, p. 33-50, 2008.

CARMO, G. T. do; PESSANHA, J. H. da S. Evasão versus permanência escolar: desafios para o PROEJA. CONINTER 3, 2014, pp. 1-16. Congresso Internacional Interdisciplinar em Sociais e Humanidades. Salvador (BA), 08 e 10 de outubro de 2014.

DORNELES, B. V. A educação para o século XXI: questões e perspectivas. Revista Pedagógica Pátio, Porto Alegre: Artmed, Ano IX, n. 33, fev/abr, 2005.

FRIGOTTO, G. A produtividade da escola improdutiva 30 anos depois: regressão social e hegemonia às avessas. Revista TrabaIho Necessário, ano 13, n. 20, p. 206-233, 2015.

HADDAD, S; Di PIERRO, M. C. Escolarização de jovens e adultos. Revista Brasileira de Educação, n. 14, p. 108-194, maio/ago. 2000.

PAIVA, J.; SOARES, A. C. da S.; BARCELOS, L. B. Educação Continuada, Qualidade e Diversidade: Um olhar complexo sobre apren- dentes Jovens e Adultos. Revista Debates em Educação, Maceió, v. 6, n. 11, p. 17-38, jan./jun. 2014.

PEREIRA, R. M. A formação do professor do Proeja: implicações na prática pedagógica. Pesquisa em educação: desenvolvimento, ética e responsabilidade social. In: $V$ ENCONTRO DE PESQUISA EM EDUCAÇÃO EM ALAGOAS. 5, 2010, Maceió. Anais... Maceió: UFAL, 2010. p. 01-15.

SANTOS, M. A. F. Perfil do aluno da EJA/Médio na Escola Dr. Alfredo Pessoa de Lima. 69 f. Monografia (Gestão de Ensino). Universidade Federal da Paraíba: Bananeiras/PB, 2007.

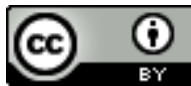

License information: This is an openaccess article distributed under the terms of the Creative Commons Attribution License, which permits unrestricted use, distribution, and reproduction in any medium, provided the original work is properly cited.

Artigo recebido em 07 de dezembro de 2015.

Avaliado em 27 de setembro de 2016.

Aceito em 21 de outubro de 2016.

Publicado em 03 de novembro de 2016.

Como citar este artigo (ABNT):

MOREIRA, Raquel Veggi; LIRIO, Larissa Mendonça. O aluno do PROEJA no município de Muriaé: Escola Municipal "Professora Odaléia Morais de Azevedo". Estação Científica (UNIFAP), Macapá, v. 6, n. 2, p. 117126, maio/ago. 2016. 